\title{
The localization of primary efferent sympathetic neurons innervating the porcine thymus - a retrograde tracing study
}

\author{
Paweł Kulik, Anna Zacharko-Siembida, Marcin B. Arciszewski \\ Department of Animal Anatomy and Histology, Faculty of Veterinary Medicine, University of Life Sciences, \\ Lublin, Poland
}

Received November 15, 2016

Accepted May 31, 2017

\begin{abstract}
The autonomic nervous system is a sophisticated and independent structure composed of two antagonistic (opposing) divisions (sympathetic and parasympathetic) that control many vital functions including: homeostasis maintenance, heart rate, blood circulation, secretion, etc. Thymus is one of the most important primary lymphoid organs playing a role in the developing of a juvenile's immune system mainly by maturation, development, and migration of T-cells (T lymphocytes). In the last decades, several studies identifying sources of the thymic autonomic supply have been undertaken in humans and several laboratory rodents but not in higher mammals such as the pig. Therefore, in the present work, retrograde tracing technique of Fast Blue and DiI was used to investigate the sources of sympathetic efferent supply to the porcine thymus. After Fast Blue injection into the right lobe of the thymus, the presence of Fast Bluepositive neurons was found in the unilateral cranial cervical ganglion $(82.8 \pm 3.0 \%$ of total Fast Blue-positive neurons) as well as in the middle cervical ganglion (17.2 $\pm 3.0 \%)$. Injection of DiI resulted in the presence of retrograde tracer in neurons of the cranial cervical ganglion $(80.4 \pm$ $2.3 \%$ of total amount of DiI-labelled neurons), the middle cervical ganglion (18.4 $\pm 1.9 \%$ ), and the cervicothoracic ganglion $(1.2 \pm 0.8 \%)$. The present report provides the first data describing in details the localization of primary efferent sympathetic neurons innervating the porcine thymus.
\end{abstract}

Fast Blue, DiI, paravertebral ganglia, lymphoid organ, mammals

A large majority of internal organs are supplied from both sympathetic and parasympathetic sources of the autonomic nervous system (ANS). Of key importance for autonomic reflexes are the interactions between biologically active substances that are stored and released from presynaptic neurons and receptors that are present in the effector cells (McCorry 2007). However, organ functional integrity and its defense line are dependent and regulated not only by ANS. Similar tasks are assigned to endocrine as well as immunological systems, in particular to lymphoid organs (Schultz and Grieder 1987). All three systems are structurally much expanded and use their own regulatory molecules (hormones, cytokines, and neurotransmitters/neuropeptides) for internal communication purposes. Therefore, numerous functional interactions between different regulatory cells are frequently observed (Gaillard 2002). These phenomena explain why many researchers concentrated their efforts to study the nervous supply to lymphoid organs and the influence of ANS on the activity of immunological cells (Bellinger and Lorton 2014). The thymus gland, belonging to primary lymphoid organs, has a specific place in the mammalian immunological system mainly due to very complicated cellular structure and multipotent functions. Using the histochemical technique, the expression of fluorescent of glyoxylic acid (noradrenergic neuron marker) or acetylcholinesterase (AChE; marker of cholinergic neurons) has been studied in the thymus of numerous mammals, including the mouse (Bulloch and Pomerantz 1984), the rat (al-Shawaf et al. 1991; Mićić et al. 1992), the rabbit (Felten et al. 1981), and humans (Topilko and Caillou 1985; Páldi-Haris et al. 1990). Additionally, primary antisera against major autonomic

Address for correspondence:

Dr. Anna Zacharko-Siembida

Department of Animal Anatomy and Histology

Faculty of Veterinary Medicine, University of Life Sciences

Akademicka 12, 20-033, Lublin, Poland 
neurotransmitters as well as neuropeptides/neuropeptide receptors have been applied in immunohistochemical studies in rats (Gomariz et al. 1990; Kendall and al-Shawaf 1991; Bellinger et al. 1997), mice (Delgado et al. 1996; Mitchell et al. 1997), and humans (Lara-Marquez et al. 2000; Mignini et al. 2011). Experimental procedures like chemical sympathectomy with 6-hydroxydopamine (6-OHDA) or guanethidine (Kendall and al-Shawaf 1991), surgical denervation of the sympathetic chain, ablation of the vagus or recurrent laryngeal nerve (Mignini et al. 2010) allowed to determine preliminary sources of sympathetic and parasympathetic innervation to the rat thymus. A substantial progress in neuroanatomical studies on the thymus innervation has been achieved with the use of the retrograde tracing technique utilizing retrograde neuronal tracers such as Fast Blue (FB) (Kummer and Oberst 1993), Fluoro-Gold (FG) (Tollefson and Bulloch 1990), Diamidino Yellow (DY) (Dovas et al. 1998), or horseradish peroxidase (HRP) (Bulloch and Moore 1981). More recently, the central sympathetic centres projecting the rat thymus were transneuronally visualized with the use of the pseudorabies virus (Trotter et al. 2007). As mentioned above, so far most of researchers focused on the innervation of the rodents' thymus whereas reports describing sources of the nerve supply to the thymus in large mammals are scarce. Therefore, in the present study, the localization of porcine thymus-projecting efferent neurons has been determined using two different neuronal tracers (Fast Blue and DiI). The choice of the pig as an experimental animal is justified as this animal species shows numerous anatomical, physiological, and genetic similarities to humans which makes it an excellent animal model for use in various scientific studies (Lu o et al. 2012; Mair et al. 2014).

\section{Materials and Methods}

Experimental animals and anaesthesia

All experimental procedures were carried out with the approval of the responsible Local Ethics Committee (number 1/2014) and were in agreement with the "Guide for the care and use laboratory animals" (NAP publication, revised in 2011). For retrograde tracing experiments, five crossbred Polish Landrace $\times$ Pietrain $(n=5)$ piglets (three weeks old, weighing ca. $10 \mathrm{~kg}$ ) of both sexes were used. Each piglet was purchased from a different litter. The animals were sedated with an intramuscular injection $\left(2 \mathrm{mg} / \mathrm{kg} \mathrm{b.w.)}\right.$ of azaperone (Stresnil ${ }^{\circledR}$, Janssen Pharmaceutica N.V., Belgium). To induce a satisfactory level of a deep anaesthesia, intravenous injection (4-6.5 $\mathrm{mg} / \mathrm{kg}$ b.w.) of propofol (Scanofol ${ }^{\circledR}$, ScanVet, Gniezno, Poland) mixed with ketamine (2-6 mg/kg b.w.; Bioketan ${ }^{\circledR}$; Vetoquinol Biowet, Gorzów Wielkopolski, Poland) and atropine $\left(0.05 \mathrm{mg} / \mathrm{kg}\right.$ b.w.; Atropinum Sulfuricum ${ }^{\circledR}, \mathrm{WZF}$, Polfa Warszawa, Poland) was given. Pain relief was achieved by a single intravenous injection $(15-50 \mathrm{mg} / \mathrm{kg}$ b.w.) of metamizole sodium (Injectio Pyralgini ${ }^{\circledR}$, Biowet Puławy, Poland).

Injection of retrograde tracers

Two different retrograde tracers were used. The first one was Fast Blue (FB; EMS-Chemie GmbH, Gross Umstadt, Germany) which is well soluble in water and labels cell cytoplasm. The second one was DiI (D-3911; Molecular Probes, Eugene, Oregon, USA) which shows a high affinity to lipophilic binding to neuronal membrane and stains the entire cell. Because DiI is poorly soluble in water, the tracer was dissolved in dimethyl sulphoxide (DMSO), which additionally improved the tracer penetration.

In all experimental animals, a neck skin incision (approx. $4 \mathrm{~cm}$ ) in the tracheal region was made, and the left and right lobes of the thymus were exposed. In all animals, the injection of a total of $50 \mathrm{ml}$ of $5 \%$ FB into the right lobe of the thymus was done using the Hamilton syringe equipped with a 26 gauge needle. In each animal, 10 separate injections for $5 \mathrm{ml}$ each, evenly distributed throughout the right lobe, were given. In order to minimalize the tracer leakage, after each injection the needle was kept for $1 \mathrm{~min}$ and carefully wiped out with a cotton bud. Finally, the right lobe of the thymus was gently removed and separated from the left lobe. Next, using a brand new Hamilton syringe equipped with a 26 gauge needle, the left lobe of the thymus was injected with a total of $50 \mathrm{ml}$ of $5 \%$ DiI (10 separate injections of $5 \mathrm{ml}$ each). The analogous tracer injection protocol as presented above for FB was applied. The skin wound was closed with surgical staples and the animals were treated with amoxicillin (Betamox $^{\circledR}$, ScanVet Gniezno, Poland; $15 \mathrm{mg} / \mathrm{kg}$ b.w.) for the next four days.

Tissue collecting and processing

After a three weeks of post-operative period, the animals were deeply re-anaesthetised and transcardially perfused with $4 \%$ solution of buffered $(\mathrm{pH}=7.2)$ paraformaldehyde. For further studies, the sympathetic bilateral cranial cervical ganglion (CCG), bilateral middle cervical ganglion (MCG), bilateral cervicothoracic ganglion 
(CTG), bilateral $\mathrm{Th}_{2}-\mathrm{Th}_{14}$ sympathetic chain ganglia (SCG) as well as coeliac-mesenteric ganglion (CaMG) were dissected, washed in $0.9 \%$ sodium chloride and post-fixed for $1 \mathrm{~h}$ in the same fixative. For cryoprotection, the dissected material was placed in $30 \%$ cold $\left(+4{ }^{\circ} \mathrm{C}\right)$ sucrose solution and kept until it sank into the bottom of the container (approx. 3 weeks). The material was embedded in tissue-tek (Tissue-Tek ${ }^{\circledR}$ OCT $^{\mathrm{TM}}$ Compound, Sakura, Holland) and cut using the cryostat (HM50 Kriostar, Leica, Germany) into $10 \mu \mathrm{m}$ serial sections. Every third section was mounted onto a silanized microscope glass slide (SuperFrost ${ }^{\circledR}$ Plus, Menzel-Gläser, Germany) and stored at $-20{ }^{\circ} \mathrm{C}$ until further analysis was made. The slides were viewed under a spinning disk confocal microscope (BX-DSU Olympus, Nagano, Japan) equipped with a interference filters optimized for the detection of FB (MNU2, Olympus) and DiI (MWIY2, Olympus).

\section{Counting and statistics}

All FB-positive and DiI-positive neurons were counted. The numerical data are presented as mean \pm S.D. The numbers of FB-labelled neurons found in particular ganglia were presented either as absolute values or as a percentage relative to the total population of FB-positive neurons. The numbers of DiI-labelled neurons found in particular ganglia were presented either as absolute numbers or as a percentage relative to the total population of DiI-positive neurons. Comparisons between homologous and non-homologous populations of retrogradely labelled neurons were calculated using one-way analysis of variance test (ANOVA) followed by Bonferroni's post-hoc test. The level of $P<0.05$ was considered to be significant.

\section{Results}

\section{FB-positive neurons}

Injection of $\mathrm{FB}$ into the right thymus lobe resulted in the presence of FB-labelled sympathetic neurons only in the right $\mathrm{CCG}$ and the right MCG. No presence of FBpositive perikarya was found in the right $\mathrm{CTG}$ and $\mathrm{Th}_{2}-\mathrm{Th}_{14} \mathrm{SCG}, \mathrm{CaMG}$ or in any of the contralateral sympathetic ganglia (Table 1). In general, FB-positive neurons were bright and highly fluorescent and well visible in relation to the background. In the vast majority of labelled neurons the presence of FB was limited to the cell soma, however, in some neurons the presence of very short FB-positive nerve processes was also observed. In the right CCG as many as $609 \pm 80 \mathrm{FB}$-positive neurons $(\mathrm{n}=5)$ were found evenly distributed throughout the ganglion (Plate I, Fig. 1A). FB-labelled neurons found in the right SCG constituted $82.8 \pm 3.0 \%$ of the total population of FB-positive sympathetic neurons. In the right MCG, the population of FB-positive sympathetic neurons was $125 \pm 15(\mathrm{n}=5)$ and constituted a significantly smaller $(17.2 \pm 3.0 \%$; vs. CCG; $P<0.05)$ population of total FB-labelled periakrya. In MCG, FB-positive neurons were randomly scattered throughout the ganglion. The vast majority of CCG FB-positive as well as MCG-positive neurons were classified as oval or spindle middle in size (with diameter between 25 and $50 \mu \mathrm{m}$ ) cells (Plate I, Fig. 1B). In both ganglia, the remaining 10\% of FB-positive neurons were categorized as small round cells (with diameter less than $25 \mu \mathrm{m}$ ).

Table 1. The percentages of retrogradely labelled neurons found in sympathetic ganglia after the unilateral injection of FB or DiI into the porcine thymus. (Abbreviations: FB - Fast Blue; n/d - not detected; CCG - cranial cervical ganglion; MCG - middle cervical ganglion; CTG - cervicothoracic ganglion; SCG - sympathetic chain ganglia; CaMG - coeliac-mesenteric ganglion)

\begin{tabular}{lccccc}
\hline & CCG & MCG & CTG & $\mathrm{Th}_{2}-\mathrm{Th}_{14}$ SCG & CaMG \\
\hline Fast Blue & $82.8 \pm 3.0 \%$ & $17.2 \pm 3.0 \%$ & $\mathrm{n} / \mathrm{d}$ & $\mathrm{n} / \mathrm{d}$ & $\mathrm{n} / \mathrm{d}$ \\
DiI & $80.4 \pm 2.3 \%$ & $18.4 \pm 1.9 \%$ & $1.2 \pm 0.8 \%$ & $\mathrm{n} / \mathrm{d}$ & $\mathrm{n} / \mathrm{d}$ \\
\hline
\end{tabular}

\section{DiI-positive neurons}

After the injection of DiI into the left thymus lobe the presence of DiI-labelled neurons was found in the sympathetic unilateral CCG, MCG as well as STG. No DiI-positive perikarya were detected neither in unilateral $\mathrm{Th}_{2}-\mathrm{Th}_{14} \mathrm{SCG}, \mathrm{CaMG}$ nor in all contralateral sympathetic ganglia. In general, in DiI-positive neurons the presence of highly fluorescent 
microgranules in the entire soma was seen which allowed to easily differentiate tracerlabelled neurons. Beside the neuronal soma, the presence of DiI was also observed in moderate numbers of short nerve processes (presumably axons or dendrites; Plate I, Fig. 1C). On average $817 \pm 83(n=5)$ DiI-labelled cells $(80.4 \pm 2.3 \%$ of total DiI-positive sympathetic neurons) were found in the left CCG. In left MCG, as many as $186 \pm 16$ of neurons $(18.4 \pm 1.9 \%)$ were found to be positive to DiI, and that population was significantly lower than the analogous one found in the CCG $(P<0.05)$. In both CCG and MCG, the vast majority (ca. 80\%) of DiI-positive neurons were of medium size, and of oval, round or spindle shape. The remaining $20 \%$ were categorized as small oval/round neurons. In both CCG and MCG, the presence of large neurons (with a diameter larger than $50 \mu \mathrm{m}$ ) was found occasionally (Plate I, Fig. 1D, E), however, those neurons constituted less than $1 \%$ of the total DiI-labelled cells. In general, no distinct distribution pattern of DiI-labelled neurons was observed in the CCG, however, in some cross-sections peripherally located DiI-positive cells lying in close vicinity to the ganglionic capsule were regularly detected. Only $12 \pm 7(\mathrm{n}=5)$ DiI-positive medium-size, oval neurons were found in the left CTG (Plate I, Fig. 1F). The latter population constituted $1.2 \pm 0.8 \%$ of the total DiI-labelled neurons and was significantly the smallest compared to CCG or MCG $(P<0.05)$. Although the absolute number of DiI-positive neurons found in CCG was significantly higher $(P<0.05)$ than the FB-positive ones, no significant differences were found comparing the mean percentages of both populations $(80.4 \pm 2.3 \%$ of DiI-positive vs. $82.8 \pm 3.0 \%$ of FB-positive). Similarly, the percentages of DiI-positive and FB-positive neurons found in the MCG was significantly $(P<0.05)$ the same $(18.4 \pm 1.9 \%$ vs. $17.2 \pm 3.0 \%$, respectively).

\section{Discussion}

In the present study we described for the first time the sources of primary efferent neurons supplying the porcine thymus. The application of two different retrograde tracers (FB and DiI) led to slightly different results. Since FB-positive neurons were detected only in the CCG and MCG, the use of DiI allowed us to detect the minor population $(<1 \%)$ of thymus-supplying sympathetic neurons also in the CTG. Because no leakage of tracer from the injection site was noted, we concluded that the CTG should be also considered as an additional source of sympathetic neurons projecting to the porcine thymus. The observed discrepancies may be explained by the physicochemical properties of both tracers (Schofield 2008) as well as the properties of the vehicles used. According to the supplier's recommendation, DiI was dissolved in DMSO, which per se increases the cell membranes permeability (He et al. 2012) and thus may help the tracer to spread inside the organ. This simply explains why substantially greater total numbers of thymusprojecting neurons were observed after DiI than FB application. It must be also kept in mind that the fading of signals caused by free radicals is a serious limitation in case of certain fluorescent tracers like FB but not DiI, which would further explain the differences observed. However, no matter which tracer was used, our results showed that the CCG is the main source of primary efferent neurons innervating the porcine thymus, whereas in the MCG and CTG only a minor population of thymus-projecting neurons is present. Moreover, our study indicates that the use of DiI is more effective than FB, and DiI might be a tracer of choice in classical neuroanatomical research aiming at the identification of primary efferent sympathetic neurons supplying the porcine thymus. In previous studies utilizing HRP as a retrograde tracer, it has been shown that at the central level, mouse thymus projecting neurons originate from the ventral horn of the cervical spinal cord and from the dorsal and ventral brainstem complex of the nucleus of the vagus nerve (Bulloch 1998). Recently, using the pseudorabies virus Trotter et al. (2007) were able to show that the sympathetic neurons innervating the thymus in rats are also localized in the spinal 
$\mathrm{T}_{1}-\mathrm{T}_{7}$ intermediolateral cell column, central autonomic nucleus, intercalated nucleus as well as in certain nuclei of the medulla oblongata, pons and hypothalamus but not in the dorsal motor nucleus. In the rat, surgical sympathectomy resulted in a substantial reduction of the thymus-innervating noradrenergic nerve fibres whereas the opposite effect was noted when the CCG was directly electrostimulated (Artico et al. 2002). In contrast, in another study two weeks after the removal of bilateral CCG, no significant changes in the thymic level of noradrenaline or distribution and density of the thymus-supplying autofluorescent fibres were noted (Milosevic et al. 1994). However, the injection of HRP-conjugated wheat germ agglutinin (HRP-WGA) into the rat and mouse thymus allowed to localize labelled neurons in the ganglia of the sympathetic chains from the CCG caudal to the T3 (Nance et al. 1987). Similarly, in retrograde tracing experiments with the use of a cholera toxin B subunit, Lee et al. (1998) were able to observe labelled neurons not only in the CCG, MCG, and CTG but also in the $\mathrm{T}_{2}-\mathrm{T}_{8}$ SCG. It is noteworthy that in the present study we found no FB-positive/DiI-positive neurons in any of the SCG which may indicate the presence of species-specific differences in thymus innervation between various mammals.

In conclusion, sympathetic primary efferent neurons projecting to the porcine thymus are localized in the CCG (main source), the MCG, and the CTG (minor sources). The application of DiI as a retrograde tracer is recommended for classic porcine thymus innervation studies.

\section{References}

Al-Shawaf AA, Kendall MD, Cowen T 1991: Identification of neural profiles containing vasoactive intestinal polypeptide, acetylcholinesterase and catecholamines in the rat thymus. J Anat 174: 131-143

Artico M, Cavallotti C, Cavallotti D 2002: Adrenergic nerve fibres and mast cells: correlation in rat thymus. Immunol Lett 84: 69-76

Bellinger DL, Lorton D 2014: Autonomic regulation of cellular immune function. Auton Neurosci 182C: 15-41

Bellinger DL, Lorton D, Horn L, Brouxhon S, Felten SY, Felten DL 1997: Vasoactive intestinal polypeptide (VIP) innervation of rat spleen, thymus, and lymph nodes. Peptides 18: 1139-1149

Bulloch K, Moore RY 1981: Innervation of the thymus gland by brain stem and spinal cord in mouse and rat. Am J Anat 162: 157-166

Bulloch K, Pomerantz W 1984: Autonomic nervous system innervation of thymic-related lymphoid tissue in wildtype and nude mice. J Comp Neurol 228: 57-68

Bulloch K 1998: A comparative study of the autonomic nervous system innervation of the thymus in the mouse and chicken. Int J Neurosci 40: 129-140

Delgado M, Martinez C, Johnson MC, Gomariz RP, Ganea D 1996: Differential expression of vasoactive intestinal peptide receptors 1 and 2 (VIP-R1 and VIP-R2) mRNA in murine lymphocytes. J Neuroimmunol 68: 27-38

Dovas A, Lucchi ML, Bortolami R, Grandis A, Palladino AR, Banelli E, Carretta M, Magni F, Paolocci N 1998: Collaterals of recurrent laryngeal nerve fibres innervate the thymus: a fluorescent tracer and HRP investigation of efferent vagal neurons in the rat brainstem. Brain Res 809: 141-148

Felten DL, Overhage JM, Felten SY, Schmedtje JF 1981: Noradrenergic sympathetic innervation of lymphoid tissue in the rabbit appendix: further evidence for a link between the nervous and immune systems. Brain Res Bull 7: 595-612

Gaillard RC 2002: Neuroendocrine-Immune Interactions. Frontiers of Hormone Research vol. 29, Karger

Gomariz RP, Lorenzo MJ, Cacicedo L, Vicente A, Zapata AG 1990: Demonstration of immunoreactive vasoactive intestinal peptide (IR-VIP) and somatostatin (IR-SOM) in rat thymus. Brain Behav Immun 4: 151-161

He F, Liu W, Zheng S, Zhou L, Ye B, Qi Z 2012: Ion transport through dimethyl sulfoxide (DMSO) induced transient water pores in cell membranes. Mol Membr Biol 29: 107-113

Kendall MD, al-Shawaf AA 1991: Innervation of the rat thymus gland. Brain Behav Immun 5: 9-28

Kummer W, Oberst P 1993: Neuronal projections to the guinea pig stellate ganglion investigated by retrograde tracing. J Auton Nerv Syst 42: 71-80

Lara-Marquez ML, O’Dorisio MS, Karacay B 2000: Vasoactive intestinal peptide (VIP) receptor type 2 (VPAC2) is the predominant receptor expressed in human thymocytes. Ann NY Acad Sci 921: 45-54

Lee CH, Jang KS, Kim HT, Lee MS 1998. The localization of efferent and afferent neurons innervating the rat thymus using the neural tracers. Korean J Anat 31: 71-80

Luo Y, Lin L, Bolund L, Jensen TG, Sørensen CB 2012: Genetically modified pigs for biomedical research. J Inherit Metab Dis 35: 695-713

Mair KH, Sedlak C, Käser T, Pasternak A, Levast B, Gerner W, Saalmüller A, Summerfield A, Gerdts V, Wilson HL, Meurens F 2014: The porcine innate immune system: An update. Dev Comp Immunol 45: 321-343 
McCorry LK 2007: Physiology of the autonomic nervous system. Am J Pharm Educ 71: article 78

Mićić M, Leposavić G, Ugresić N, Bogojević M, Isaković K 1992: Parasympathetic innervation of the rat thymus during first life period: histochemical and biochemical study. Thymus 19: 173-182

Mignini F, Sabbatini M, D’Andrea V, Cavallotti C 2010: Intrinsic innervation and dopaminergic markers after experimental denervation in rat thymus. Eur J Histochem 54: e17, 81-87

Mignini F, Sabbatini M, D'Andrea V, Cavallotti C 2011: Neuropeptides of human thymus in normal and pathological conditions. Peptides 32: 920-928

Milosevic D, Micic M, Leposavic G, Ugresic N 1994: Re-investigation of the contribution of the superior cervical ganglion to innervation of the rat thymus. Acta Vet Beograd 44: 91-98

Mitchell B, Kendall M, Adam E, Schumacher U 1997: Innervation of the thymus in normal and bone marrow reconstituted severe combined immunodeficient (SCID) mice. J Neuroimmunol 75: 19-27

Nance DM, Hopkins DA, Bieger D 1987: Re-investigation of the innervation of the thymus gland in mice and rats. Brain Behav Immun 1: 134-147

Páldi-Haris P, Szelényi JG, Nguyen TH, Hollán SR 1990: Changes in the expression of the cholinergic structures of human T lymphocytes due to maturation and stimulation. Thymus 16: 119-122

Schofield BR 2008: Retrograde axonal tracing with fluorescent markers. Curr Protoc Neurosci Chapter 1: Unit 1.17

Schultz KT, Grieder F 1987: Structure and function of the immune system. Toxicol Pathol 15: 262-264

Tollefson L, Bulloch K 1990: Dual-label retrograde transport: CNS innervation of the mouse thymus distinct from other mediastinum viscera. J Neurosci Res 25: 20-28

Topilko A, Caillou B 1985: Acetylcholinesterase in human thymus cells. Blood 66: 891-895

Trotter RN, Stornetta RL, Guyenet PG, Roberts MR 2007: Transneuronal mapping of the CNS network controlling sympathetic outflow to the rat thymus. Auton Neurosci 131: 9-20 
Plate I

Kulik P. et al.: The localization... pp. 117-122
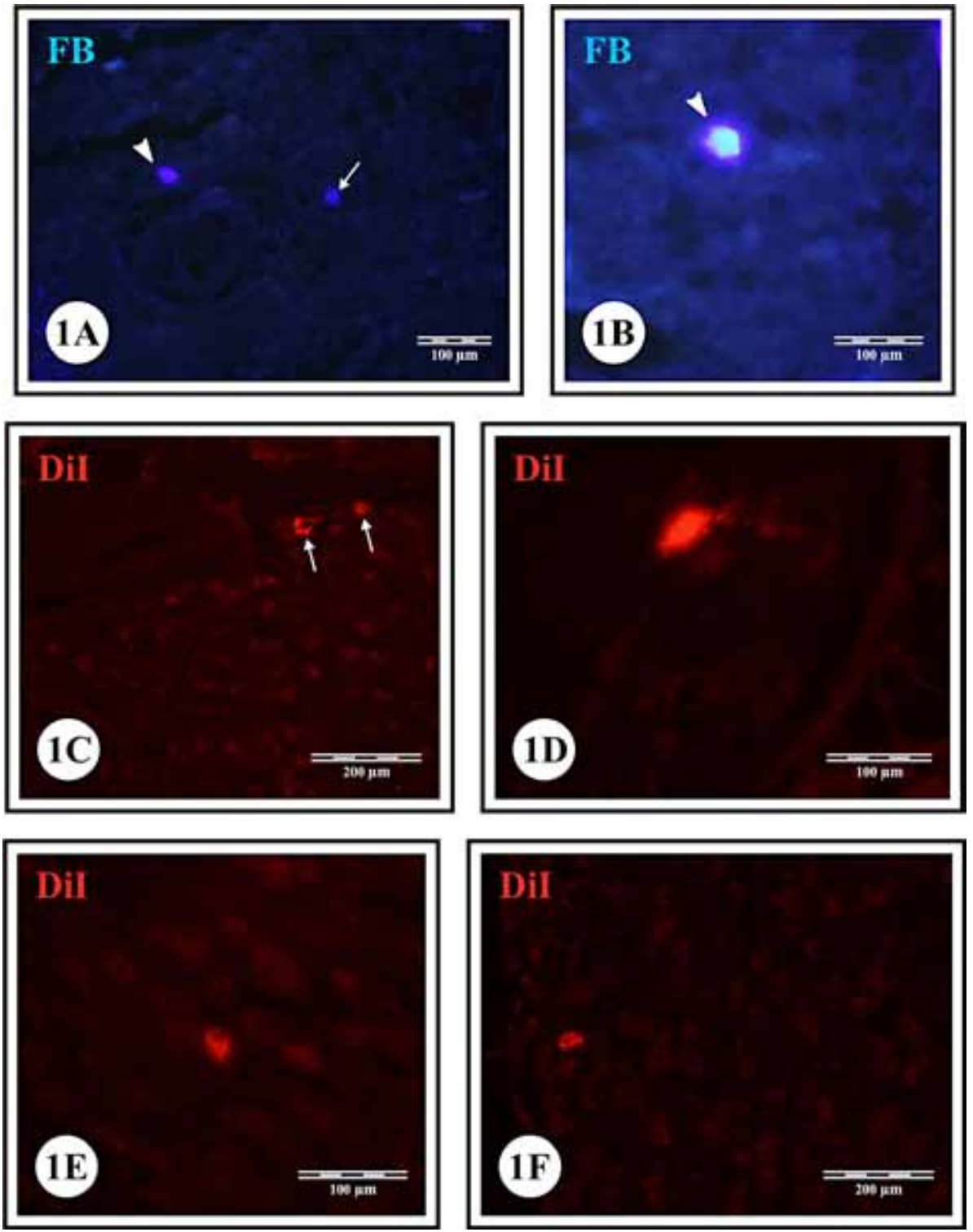

Fig. 1. Photomicrographs showing thymus-projecting retrogradely-labelled sympathetic neurons. FB injection into the thymus resulted in labelling of small-sized and middle-sized neurons of cranial cervical ganglion CCG (arrow and arrowhead respectively in A) as well in middle cervical ganglion (arrow in B). After the retrograde labeling of the thymus with DiI, the presence of DiI-positive middle sized-neurons with short DiI-positive processes (arrows in C) as well as single large DiI-positive cells (D) were seen in CCG. Micrographs (E) and (F) depicts thymus-projecting DiI-positive neurons found in MCG and CTG (respectively). (Abbreviations: FB - Fast Blue; CCG - cranial cervical ganglion; $\mathrm{MCG}$ - middle cervical ganglion; CTG - cervicothoracic ganglion). 